\title{
95-116
}

\section{NIETZSCHE Y LA CONCEPCIÓN DE LA NATURALEZA} COMO CUERPO ${ }^{1}$

Nietzsche and the concept of nature as a Body

\author{
Ricardo Espinoza Lolas* \\ Esteban Vargas** \\ Paula Ascorra Costa***
}

Resumen

Este artículo indaga en la concepción de Naturaleza del filósofo F. Nietzsche (1844-1900). Tal concepción nace en diálogo crítico con la filosofía de la época, en especial aquella que va desde el criticismo de Kant al idealismo absoluto de Hegel y que atraviesa todo un modo de ser y de comprender el mundo, la Modernidad. De allí se levanta la figura del dios griego Dioniso, como una imagen que expresa ese rasgo instantáneo de la Naturaleza que se muestra plenamente como cuerpo.

Palabras clave: Nietzsche, naturaleza, cuerpo, dioniso, kant, hegel.

\section{Abstract}

This article explores the conception of Nature of the philosopher F. Nietzsche (1844-1900). Such a concept was born in critical dialogue with the philosophy of the era, especially that one which goes from Kant's criticism to Hegel's absolute idealism and that considers a whole way of being and understanding the world, i.e. the Modernity. From here, the figure of the Greek god Dionysus arises as an image that expresses the instant trait of nature showing itself as a body.

Key words: Nietzsche, nature, body, dionysus, kant, hegel.

“...que tú eres para mí una pista de baile para azares divinos, que tú eres para mí una mesa de dioses para dados y jugadores divinos”! (F. Nietzsche, Así habló Zaratustra 258).

\section{INTRODUCCIÓN}

Un tema relevante en filosofía es poder precisar conceptualmente la "unidad" de las cosas, unidad que llamamos, simplemente: "Naturaleza”. Esta unidad ha sido entendida de múltiples maneras, ya sea como un mero "conjunto" de todo lo que existe, ya sea como algo que posee cierta "unidad" propia. Dentro de este segundo sentido hay muchos matices. La unidad podría

\footnotetext{
${ }^{1}$ Este artículo es parte del Proyecto Fondecyt $\mathrm{N}^{\circ}$ 1110507: Realidad y cuerpo en Zubiri. Investigador Responsable: Dr. Ricardo Espinoza Lolas. Y han colaborado los alumnos tesistas: Mg. Eugenia Colomer Espinoza (eugenia.colomer@ucv.cl) y Mg. Ronald Durán Allimant (ronaldbeat@gmail.com).
} 
ser concebida como el "orden” (cosmos) resultante de las naturalezas de cada una de las cosas ya constituidas. Naturaleza sería un principio de "cada” cosa, la cual lleva intrínsecamente la ordenación a las demás. Luego la Edad Moderna conceptuó esta unidad de otro modo. Se entendió la unidad como una "función" de unas cosas respecto de otras, función que tiene el carácter de una "ley necesaria”, pues la Naturaleza se comprendió desde el horizonte de la exterioridad en contraposición al espíritu que era lo propio de la interioridad. Pero esta unidad no necesariamente debe ser entendida como una ley matemática, sino como algo que se nos impone en el cuerpo y que a la vez es el mismo cuerpo en su carácter experiencial; tal es lo que piensa Nietzsche y lo veremos en este artículo.

Para aclarar esto hay que señalar que uno de los momentos fundamentales de la Naturaleza es su carácter material. Este concepto de materia se suele entender en oposición a algo. Así, materia se ha entendido, en primer lugar, en oposición a la forma. Aristóteles es el mayor representante de esta postura. Aquí la materia se ha entendido como el "material" de lo que está hecho algo. La materia por excelencia sería la "materia prima”, aquello que "potencialmente" puede serlo todo, pero que en sí misma no es nada en acto como la forma. En segundo lugar, se ha entendido la materia en oposición al espíritu. La materia es así pura "exterioridad", a diferencia de lo espiritual que es aquello que puede volver sobre sí mismo y que es, por lo tanto, “interioridad”. Es un pensamiento que se inicia en la Edad Media y que se acentúa en la modernidad, principalmente en Descartes y el idealismo alemán; y está a la base para entender la Naturaleza como ley (Hegel, Lecciones sobre la filosofía de la historia natural 62). Por último, materia se ha entendido como el aspecto "sensible" que se muestra en lo aprehendido. Materia es así lo "sensible" en oposición a otros modos de lo aprehendido como lo intelectivo o lo racional. Esta conceptuación, a grandes rasgos, se aprecia en Kant (Principios metafísicos de la ciencia de la naturaleza 46), abunda en el materialismo del siglo XIX (Lenin 134) y en la fenomenología (Husserl § 85) (Zubiri, Espacio. Tiempo. Materia). Desde estas tres ideas de materia, que no son completamente excluyentes, los filósofos han intentado concebir la "unidad" de las cosas materiales que llamamos Naturaleza. Veamos cómo la expresa Nietzsche.

NATURALEZA Y MODERNIDAD

Para entender, en parte, la sentencia de Así habló Zaratustra que abre este escrito pueden ser un punto de partida las siguientes palabras del último Nietzsche en su "tristemente célebre" El Anticristo de septiembre de 1888

"Yo no sé qué hacer; yo soy todo eso que no sabe qué hacer" — suspira el hombre moderno. De esa modernidad hemos estado enfermos - de paz ambigua, de compromiso cobarde, de toda la virtuosa suciedad propia de sí y 
el no moderno. Esa tolerancia y largeur [amplitud] de corazón que "perdona" todo porque "comprende" todo es sirocco [siroco] para nosotros... (27-28).

El problema es pensar desde otro horizonte que el de la modernidad, pues desde este horizonte las cosas y el hombre son esencialmente entendidas desde un carácter no "danzarín”: las cosas desde leyes y el hombre desde deberes. Tanto el hombre como la Naturaleza ya no "bailan sobre los pies del azar", sobre los pies de los "dioses", sino sobre el fundamento que los mide, los relaciona y les da a cada uno su justo lugar dentro del tramado lógico de lo necesario, universal y a priori (Zubiri, Naturaleza, Historia, Dios 343-344). ¿Cómo pensar de un modo no moderno, no dialéctico, la articulación misma entre naturaleza y espíritu? Una Naturaleza siempre pensada como exterioridad de fuerzas, desde la intuición y la belleza; y un espíritu, el hombre, pensado desde la interioridad, desde la reflexión y la verdad (Hegel, Fenomenología del espíritu 213). ¿Cómo pensar la Naturaleza lejos de categorías matematizables, medibles o exteriorizantes? Esta pregunta no solamente fue el motor que movió el pensamiento de Nietzsche, sino que es la pregunta que movió al empirismo, al racionalismo, al criticismo, al idealismo, al romanticismo, al positivismo, etc., pero las respuestas de estas filosofías siempre fueron unilaterales; mostraban una "perspectiva" muy pobre del problema; una perspectiva con ansias de absolutez; con ansias de dar "una" respuesta total.

Sabemos, después de la filosofía del idealismo, que no podemos pensar la Naturaleza en y por sí misma (como si fuera algo en sí), este camino es inviable para el hombre. Pero tampoco podemos dar cuenta del hombre en y por sí mismo; también es inviable caminar por esa senda. No podemos pensar la Naturaleza en términos mecánicos de mera ley (como algo que está ahí, como un cierto tipo de centro, de estructura delante del hombre para que él la interrogue a través del instrumento del experimento) (Espinoza, Estructura 332) y menos al hombre como un cierto en sí que también funcione como estructura y centro lógico que lo rige "desde dentro de sí"

La cuestión está en saber hasta qué punto ese juicio favorece la vida, conserva la vida, conserva la especie; y nosotros estamos inclinados por principio a afirmar que los juicios más falsos... son los más imprescindibles para nosotros, que el hombre no podría vivir si no admitiese las ficciones lógicas, si no midiese la realidad con el metro del mundo puramente inventado de lo incondicionado, idéntico-a-sí-mismo (F. Nietzsche, Más allá del bien y del mal 25-26).

¿Qué nos queda? ¿Hay un puente que nos permita el tránsito entre naturaleza y espíritu? ¿Es una solución posible la vía que intentó el idealismo alemán, vía que realiza el camino entre naturaleza y espíritu desde la mano de la absolutez, la idea, lo infinito? (Espinoza, "En torno al problema de Dios" ...desde la Biografía del joven Zubiri 149). Nietzsche es así de explícito: "Sin 
ningún género de dudas, los alemanes son idealistas” (Ecce homo 128), teniendo claro que este camino es por donde no debe caminar más el pensamiento. $^{2}$

Para Nietzsche el pensamiento idealista de la infinitud es imposible para pensar lo propiamente natural; la vía idealista es la vía teológica, vía que nos lleva a hundirnos más y más en el Ocaso (Untergang) de la oscura noche de la nihilidad, de una nihilidad que emerge con una fuerza tal que todo lo que toca lo neutraliza, lo despotencia y lo niega en lo más radical. ¡He ahí el poder de la "Idea”! Nietzsche lo dice claramente

Lo que cuento es la historia de los próximos dos siglos. Describo lo que viene, lo que ya no puede venir de otra manera: la ascensión del nihilismo. Esta historia ya se puede contar ahora: pues la necesidad misma está aquí trabajando (Fragmentos póstumos (1885-1889) Vol. IV 489).

Este es precisamente el problema para Nietzsche. La "ascensión del nihilismo" se impone por todas partes, su paso es inexorable y violento como el avance de un desierto. El destino del hombre estará de aquí en adelante ligado al desarrollo mismo del nihilismo, a la evolución del nihilismo. Europa se vuelve en sí misma en la historia del nihilismo. ¿Cómo salir de la nihilidad? Solamente saldremos de ella cuando derribemos a martillazos los ídolos del laberinto de la modernidad. Y cuando se desmorone el laberinto podremos vernos cara a cara con el imponente (e "impotente") minotauro que habitaba y reinaba en él; esto es, ¡Kant! El problema de la modernidad, para Nietzsche, es lisa y llanamente de modo caricaturesco el "problema de Kant" (y es en él donde comienza a darse el problema de la infinitud, desde la "cosa en sí” kantiana a la idea hegeliana solamente hay un matiz de diferencia). ${ }^{3}$

Nietzsche lleva al tribunal a la Modernidad y en esto a sus más grandes exponentes: Lutero, Kant, Wagner. Al llevarlos al tribunal cae su Dios, el en sí que ellos soportan y arrastran, y la carga pesada que ha llevado al Ocaso al hombre "moderno-camello". El "no" de los modernos es el "no" que actúa negativamente "momificando" la vida danzarina, ya de las cosas ya de los hombres. Nietzsche, a este horizonte de pensamiento, del “sí” y del “no” moderno (el horizonte dialéctico

\footnotetext{
${ }^{2}$ Respecto de Wagner y su influencia hegeliana véase (F. Nietzsche, Nietzsche contra Wagner 42)

${ }^{3}$ La disputa de Nietzsche con Kant se radicaliza a lo largo de los años y en 1888 es una disputa a muerte. Nietzsche que comenzó siendo un "hijo de su tiempo" era kantiano, como la mayoría de los de su época. Por ejemplo, su gran texto de juventud, escrito que ha marcado a múltiples filósofos posteriores a Nietzsche, Verdad y mentira en sentido extramoral de 1873 no es posible entenderlo sino desde la filosofía kantiana. Y contra este pensamiento que se expande por toda Alemania y Europa se rebela Nietzsche; en el fondo, es un ajuste de cuentas con lo más propio de sí. Lo que estaba realizando al final de su vida, era poner en el tribunal a la modernidad. ¿Qué tribunal? No es el tribunal de la razón. El tribunal es el del “cuerpo”, es el cuerpo quien juzga la razón moderna: ¡Nietzsche contra la modernidad!
} 
en el cual él siempre estará incómodo), a veces lo llama simplemente "Nihilismo". Ya no más el "sí” y el "no" moderno, no más dialéctica, ni negatividad; ${ }^{4}$ en esos opuestos no hay felicidad alguna para el hombre, para un hombre que es en la tierra, en la Naturaleza, pues en ellos radica una mera aspiración nihilista a una felicidad que no llegará en esta vida (por eso también lo llama "budismo"), a una felicidad que se promete en múltiples metas, pero con el compromiso vital del gran sacrificio que el hombre tiene que hacer: debe negarse a sí mismo en lo más propio y en ello negar su tierra, su cuerpo, su realidad. El hombre y la Naturaleza quedan subsumidos y absorbidos en meros conceptos de una razón enfermiza que niega la carne, el cuerpo, las impresiones, los sentidos, las fuerzas, las tensiones, los ritmos, los deseos, los miedos, el dolor, la muerte; niega el único y afirmativo "blasón de la necesidad del eterno Sí del ser” (F. Nietzsche, Poesía Completa (1869-1888) 81). El "sí y no" modernos niegan la sobreabundancia de un gran "Sí" que vuelve una y otra vez

... el tiempo es lo que se repite... el presente no cesa de volver. Pero, de volver como singular diferencia... la diferencia vuelve... el ser es el Retorno liberado de la curvatura del círculo, es el Volver (Foucault y Deleuze 44-45).

\section{LA NUEVA CONCEPCIÓN DE LA NATURALEZA EN NIETZSCHE}

Como se ha dicho más arriba lo que radicalmente ataca Nietzsche en su obra, especialmente al final de su vida filosófica en 1888, es el rasgo "modernokantiano", el kantismo, que constituye el horizonte de la Alemania de su época, de la Europa del siglo XIX. Es el Kant del en sí, del deber ser. ${ }^{5}$ Y esto no lo podemos olvidar al leer libros tan complejos, difíciles, molestos y duros como, por ejemplo, Así habló Zaratustra, Genealogía de la moral y El Anticristo. Digamos, además, que analizar y dar martillazos a Kant, ${ }^{6}$ en sentido amplio es dar martillazos no solamente a la filosofía (esto es lo que menos le interesa a Nietzsche) sino a la ciencia, a la religión, al arte, a la ética, a la política, etc., a saber, a todo un modo de comprender la realidad en general. La Naturaleza y el

\footnotetext{
${ }^{4}$ Aunque tal dialéctica, Nietzsche la vio desde muy joven y naciendo en la misma Grecia de la mano de Parménides. "[Parménides]... escindió limpiamente los sentidos de la facultad de pensar y abstraer como si se tratara actividades dispares; incluso destruyó el intelecto como tal y alentó la tan errónea distinción entre 'cuerpo’ y 'espíritu', que sobre todo desde Platón, pende como una maldición sobre la filosofía” (F. Nietzsche, La filosofía en la época trágica de los griegos, 85).

${ }^{5}$ Es el Kant ideológico como kantismo que se levanta desde la segunda edición de la Crítica de la razón pura de 1787 y atraviesa a todas las universidades alemanas; la primera edición de la Crítica ya no se leía ni se conocía, fue Schopenhauer el que la mando a reeditar.

${ }^{6}$ Es decir, El caso Kant, la ideología kantiana que atravesaba distintas disciplinas, ciencias, artes, política y religión de la época.
} 
hombre jamás serán sentidos en su dinámico "baile de cortejo", ${ }^{7}$ dicho plásticamente, mientras siga imperando, como una ley (la Naturaleza) y como un deber (el hombre), el laberinto paralizante y "momificante” del a priori kantiano que llega hasta el infinito hegeliano de la "idea"

Todo lo que los filósofos han venido manejando desde hace milenios fueron momias conceptuales; de sus manos no salió nada vivo real. Matan, rellenan de paja, esos señores idólatras de los conceptos, cuando adoran, -se vuelven mortalmente peligrosos para todo, cuando adoran... Lo que es no deviene; lo que deviene no es (F. Nietzsche, Crepúsculo de los ídolos 45).

¿Cómo salir de esta enfermedad de los tiempos modernos nihilistas? ¿Cómo lograr sentir las cosas en sus "pies bailarines sobre el azar”? ¿Cómo el hombre en cuanto hombre se libera de sus cadenas formales y se vuelve caminante? Para responder a esto no olvidemos la célebre fórmula nietzscheana de la felicidad: "Fórmula de nuestra felicidad: un sí, un no, una línea recta, una meta..." (El Anticristo, 27-28). ${ }^{8}$ La palabra "meta” (Ziel) está en cursiva en el original, pues no se trata de cualquier meta; por ejemplo, no son las "metas" (Ziele) de todos (serían las metas del rebaño, de la gente), las metas que todos "aspiran”, añoran; las metas que están inscritas en el futuro, en la nihilidad misma del futuro porque niegan el presente de la vida. No se trata de las metas que se nos imponen desde "fuera" de nosotros mismos (desde otra vida, desde el tránsito a través de la muerte), desde ese "no" que nos aterroriza, nos paraliza y nos detiene: "Nosotros hemos inventado el concepto 'finalidad': en la realidad falta la finalidad...” (F. Nietzsche, Crepúsculo de los ídolos 69). ${ }^{9}$

\footnotetext{
${ }^{7}$ Como lo señala Nietzsche al final de la Tercera Parte de Así habló Zaratustra a raíz de la pareja mítica Dionisos y Ariadna. Cfr. (343-358). En especial, son fundamentales los tres apartados: "Del gran anhelo" (que sabemos que este pasaje se llamaba originariamente Ariadna), (343-346), "La otra canción del baile”, (347-352) y "Los siete sellos” (que sabemos que este pasaje se llamaba Dionisos), (353-358). Véase para entender la relación de Dionisos y las mujeres y su carácter de seducción a (Daraki, 131): "Nietzsche no vería aquí motivo de escándalo. Para los dioses griegos es lícito ser seductores. Dioniso es uno de ellos, el más irresistible de todos; de todas las hierogamias griegas, la más cargada de seducción es, sin duda, la que nos lo muestra cuando llega a la isla de Naxos, a la cabeza de su cortejo musical y florido, que surge del mar, para despertar a Ariadna y someterla para siempre a su encanto". Véase, también "El lamento de Ariadna”, en (F. Nietzsche, Poesía Completa (1869-1888). Respecto a la relación de Dionisos y Ariadna Nietzsche la trabaja en distintas partes de su obra; en especial al final de ella. Y en su último libro Ecce homo es muy explícito. "Nada igual se ha compuesto nunca, ni sentido nunca, si sufrido nunca: así sufre un dios, un Dioniso. La respuesta a este ditirambo del aislamiento solar en la luz sería Ariadna... ¡Quién sabe, excepto yo, qué es Ariadna!” (105).

8 "Formel unsres Glücks: ein Ja, ein Nein, eine gerade Linie, ein Ziel...”, Der Antichrist (Werke, ZB 1165).

9 “Wir haben den Begriff 'Zweck’ erfunden: in der Realität fehlt der Zweck” Götzen-Dämmerung (Werke, ZB 978). De aquí que Klossowski entienda el eterno retorno como “círculo vicioso”, esto es, Naturaleza; cuerpo como la existencia sin sentido, sin meta que en su ir y venir circular como
} 
Esas finalidades, esas metas que nosotros mismos nos inventamos nos dicen: “iNo hagas esto ni esto otro para que seas feliz luego en la otra vida!”. De esas metas la humanidad ya está cansada. ${ }^{10}$ Sin chispa y sin presente la humanidad se extingue, se enflaquece y se diluye al igual que la Naturaleza que se desertifica y se vuelve mera nada, en un mero lugar disponible "para" ser medida, para ser matematizable; es la Naturaleza como "recipiente", como lugar donde se experimenta a través del instrumental de la racionalidad.

Nietzsche, al igual que toda una pléyade de pensadores europeos, en una época de cambios absolutamente vertiginosos, filosofa desde la articulación misma entre naturaleza y espíritu, pero lo hace de un modo único, desde el devenir mismo del hombre y no desde un carácter presumiblemente absoluto, sea de la filosofía que sea. No hay negatividad formalmente hablando en el pensamiento de Nietzsche, sino experiencia; desde el siglo XIX al XX el hombre se vuelve en un "tránsito" (Übergang) por el "ocaso" (Untergang) del siglo. El tránsito del propio Nietzsche en su vida biográfica, es el tránsito del hombre europeo moderno, nihilista-kantiano, y esto es el tránsito de una época.

El filósofo alemán decía en uno de sus aforismos póstumos de octubrenoviembre de 1888 lo siguiente: “...el Anticristo mismo es la necesaria consecuencia lógica en la evolución de un auténtico cristiano, el cristianismo mismo se supera en mí” (Fragmentos póstumos (1885-1889) Vol. IV 765). ${ }^{11}$ Esto es, una cierta forma de ser cristiano tiene que dejar su paso a otra, por esto decimos, que en Nietzsche se da en experiencia lo que en Hegel era una estructuración lógica que mentaba el dinamismo, esto es, el aufheben (el asumir, el absorber, el elevar, etc.). En Nietzsche se da existencialmente el aufgehoben (lo asumido, lo absorbido, lo elevado, etc.) hegeliano (aunque éste es siempre de tinte "lógico"), pero el aforismo, más arriba citado, es bien claro y también se habla de una "lógica necesaria" en la evolución del cristianismo. Esa lógica necesaria en evolución no es una metáfora nietzscheana, sino que pertenece a lo más radical del pensamiento alemán, pero sin dialéctica negativa. La "necesidad”, el carácter "lógico" del pensamiento y, a una, de la Naturaleza misma es parte constitutiva de

\footnotetext{
mera inmanencia permite la afirmación creadora. Véase (Klossowski, 92). "El Círculo no dice nada por sí mismo, excepto que el único sentido de la existencia es ser existencia; excepto que la significación no es nada más que una intensidad”.

${ }^{10}$ Véase (Klossowski 97). "El sentido y la meta son liquidados por el Círculo".

${ }^{11}$ Nietzsche es el "perfecto", "acabado” cristiano; es el cristiano que tiene asumido en sí mismo su propio tránsito por su ocaso, su tránsito por ese "sí” y "no” moderno-kantiano para elevarse al "sí" y "no" de los nuevos tiempos. Esto es fundamental, pues, no podemos entender a Nietzsche como "anticristiano" en el lenguaje moderno antitético de la dialéctica nihilista. Nietzsche se entiende a sí mismo como el "verdadero" cristiano. Por eso Nietzsche puede decir algo así: "La redención del cristianismo: el Anticristo (Fragmentos póstumos (1885-1889) Vol. IV 748).
} 
cierto estoicismo que está en el pensamiento nietzscheano. ${ }^{12}$ La lógica nietzscheana es siempre afirmativa (ese es el enigma de Ariadna y del eterno retorno dicho por el último Nietzsche), es corporalmente afirmativa y de allí que la negatividad del "no" ya no sea sentida como algo "meramente negativo o dialéctico", doloroso, pesado, moderno, kantiano, sino como parte necesaria del "sí" afirmativo. Estamos ante el Untergang (ocaso) en su carácter verbal untergehen (ir hacia abajo, descender, hundirse) y su Übergang (tránsito) en su respectivo übergehen (ir hacia arriba, ascender, transitar) que abre la obra Así habló Zaratustra y el caminar único que emprende el personaje de Zaratustra; su única meta, su felicidad. Estamos ya ante el "sí" y el "no" de la "fórmula de nuestra felicidad". Por esto se dice: "La grandeza del hombre está en ser un puente y no una meta: lo que en el hombre se puede amar es que es un tránsito y un ocaso" (Así habló Zaratustra 32). ${ }^{13}$

La sentencia "Dioniso contra el Crucificado", ${ }^{14}$ tan célebre, del final del texto Ecce homo mienta esencialmente "Naturaleza contra el Espíritu”, pero para eliminar malentendidos que han perjudicado bastante la interpretación de Nietzsche en el siglo recién pasado, debemos comprender bien qué es lo que entiende el filósofo alemán por Dionisos, esto es, el cuerpo, la Naturaleza. Respecto a Dionisos, el joven filósofo español, Germán Cano dice acertadamente lo siguiente: "Dioniso tiene que ver con lo irregular, lo súbito y cruel, con la omnipotencia del Ser, con la pujanza del nacer y el morir, con una 'verdad dolorosa' que desgarra al individuo” (Nietzsche, I XLI). Y para poder comprender más o menos adecuadamente lo que es Dionisos no podemos pensarlo solamente desde su obra El nacimiento de la tragedia de 1872, cuando era profesor de Basilea, pues allí nos está del todo cerrado el camino para entender lo que es la Naturaleza, ya que su rasgo nihilista schopenhaueriano y romántico wagneriano lo hace entenderla de modo antitético con el espíritu (casi dialécticamente), éste es el "sí" y "no" del moderno. Por lo señalado, "Dioniso contra el Crucificado" mienta también "Nietzsche contra la Modernidad". El nacimiento de la tragedia, entonces, nos imposibilita, en parte, entender

\footnotetext{
${ }^{12}$ Nietzsche es el pensador estoico de la modernidad tardía por excelencia; así lo hace ver en distintos pasajes de su obra; en especial, en (Más allá del bien y del mal 185). Este es un pasaje donde Nietzsche nos dice de todos los modos posibles cómo su ser estoico es constitutivo de su ser virtuoso y moral: “... ipermanezcamos duros, nosotros los últimos estoicos!, y enviemos en su ayuda todas las diabluras que aún nos quedan — nuestra náusea frente a lo burdo e impreciso, nuestro nitimur in veritum [nos lanzamos a lo prohibido], nuestro valor de aventureros...jacudamos en ayuda de nuestro 'dios' con todos nuestros 'diablos'!”.

13 "Was gross ist am Menschen, das ist, dass er eine Brücke und kein Zweck ist: was geliebt werden kann am Menschen, das ist, dass ere in Übergang und Untergang ist", Also sprach Zarathustra (Werke, ZB 281).

14 "Dioniso contra el Crucificado..." (F. Nietzsche, Ecce homo 132) “Dionisos gegen den Gekreuzigten...”, Ecce homo (Werke, ZB 1159).
} 
acabadamente a Dionisos como lo irregular (en palabras de Cano). Veamos cómo lo dice Nietzsche en 1888

Para ser justos con El nacimiento de la tragedia (1872) será necesario olvidar algunas cosas. Ha influido, e incluso fascinado, por lo que tenía de errado, por su aplicación al wagnerismo, como si éste fuese un síntoma de ascensión. Este escrito fue, justo por ello, un acontecimiento en la vida de Wagner: sólo a partir de aquel instante se pusieron grandes esperanzas en su nombre...Es políticamente indiferente —no "alemana", se dirá hoy—, desprende un repugnante olor hegeliano, sólo en algunas fórmulas está impregnada del amargo perfume cadavérico de Schopenhauer (Ecce homo 67-68).

De allí que nos fijemos en el año 1888 (último año de la vida filosófica de Nietzsche), año increíble para Nietzsche en producción de textos absolutamente radicales, innovadores y comprometidos (El caso Wagner, Ditirambos dionisíacos, Crepúsculo de los ídolos, El Anticristo, Ecce homo, Nietzsche contra Wagner; además, hay que añadir cartas, apuntes, etc.) y en Así habló Zaratustra (18831885), texto único en inspiración y construcción plástica de los conceptos. Desde estos escritos podemos, por una parte, dar con un nuevo modo de pensar; otro modo de articular el discurso y la reflexión y, por otra, vislumbrar otro modo más radical de entender, para nuestro estudio, la Naturaleza que es a la vez "naturaleza y espíritu”. Un radical "Sí del ser” que asume tanto el "sí y no” del hombre moderno. Como brillantemente resume Deleuze

El sí dionisíaco... es el que sabe decir no; es la pura afirmación, ha vencido al nihilismo y destituido a la negación de cualquier poder autónomo, pero esto porque ha puesto lo negativo al servicio de los poderes de afirmar (Nietzsche y la filosofía 259).

$\mathrm{Y}$ eso es lo que tenemos que estudiar en la fórmula nietzscheana de la felicidad, porque en ella se mienta la Naturaleza sin más, simpliciter.

\section{LA NATURALEZA EN EL ÚLTIMO NIETZSCHE}

La Naturaleza con mayúscula no puede ser dicha de un modo en que ella misma quede escindida, en el "sí" y "no" moderno, en alguna dialéctica de la especie que sea, ni en las antinomias kantianas. ${ }^{15}$ Por tal escisión y desde ella, se levanta luego la dualidad de los mundos, de lo sensible que busca ser juzgado y en ello sintetizado por algún carácter de aparente universalidad. La opción kantiana no es ya posible, por así decirlo, ni en intuición empírica ni en intuición intelectual (F. ${ }^{15}$ Es decir, de la Crítica de la razón pura a la negación determinada de la Fenomenología del
espíritu de Hegel 
Nietzsche, Más allá del bien y del mal 33); ${ }^{16}$ éste es el Dionisos y el Apolo antitéticos de Nietzsche de su etapa joven de Basilea; un decir, que en verdad, no tocaba a la cosa misma, pues se colocaba metodológica y críticamente por fuera de ella al dictar lo que ella era o, lo que de ella debíamos esperar o, lo que ella tenía que ser para el hombre o, en definitiva, prohibir que la cosa sea libremente en su "baile de fuerzas sobre los pies del azar".

La gran crítica nietzscheana se lo había llevado todo: se había llevado a Kant y el kantismo con todo lo que esto significa, esto es, con todo un horizonte de pensamiento que constituía "una” visión del mundo: la modernidad. Ya no hay espacio ni para una razón judicativa "abstracta, nihilista y paralizante”, pero tampoco para una razón escéptica "empírica del mero pasar” ni menos una romántica "oscuramente estética” (ni Hume, ni Kant, ni Wagner son válidos para Nietzsche). En definitiva, ya no se puede seguir siendo moderno; pues es anular la realidad, anular y paralizar la Naturaleza y neutralizar todas sus diferencias físicas; a saber, la "momifica” para que no pase nada, pues si no pasa nada, no tenemos nada que temer. De aquí que para el filósofo pasa por él mismo el cambio, pues él ha encontrado la felicidad, "la salida a milenios de laberinto". La felicidad del hombre "bailarín” en la Naturaleza dinámica no tiene nada que ver con la modernidad; esa felicidad es mera felicidad de la negación egoísta, como lo llama con ironía Nietzsche en Así habló Zaratustra

Y lo que en todos los mares a mí me pertenece, mi en-mí y para-mí [an und für mich] en todas las cosas, - péscame eso y sácalo fuera, sube eso hasta mí: eso es lo que aguardo yo, el más maligno de todos los pescadores (365).

En el fondo, en toda posición del saber habita una "posición”, la “mía”; esto es, un modo de agenciar poder. Pero ¿Qué le quedaba al europeo? ¿Cuál es la salida al laberinto en el que ha vagado perdido el hombre dando tumbos? ¿Un mero "positivismo" como la única herramienta, única regla, tomada de las ciencias “duras”, con lo cual se pueden levantar las llamadas ciencias "sociales”? ¿Era el positivismo ese "Gallo" que nos despertaría o por el contrario nos hundiría más y más en el abismo de un nuevo fundamento? El positivismo, como ya lo sabemos, no era nada más y nada menos que una "relación de medida", ${ }^{17}$ una regla que

\footnotetext{
16 “Llegó laguna de miel dela filosofía alemana; todos los jóvenes teólogos del Seminario (Stift) de Tubinga salieron enseguida a registrar la maleza - todos buscaban 'facultades'. ¡Y qué cosas se encontraron... Sobre todo, una facultad para lo 'suprasensible': Schelling la bautizó con el nombre de intuición intelectual y con ello satisfizo los deseos más íntimos de sus alemanes, llenos en el fondo de anhelos piadosos” (F. Nietzsche, Más allá del bien y del mal 33-34).

${ }^{17}$ Dicho en términos hegelianos del final de la lógica del ser de la Wissenschaft. Véase (Hegel, Ciencia de la lógica 396-416) "Algo que por su medida sea subsistente de suyo es en sí una relación inmediata; y ello constituye su naturaleza y el fundamento de su diferencia frente a otros” (397).
} 
permitía medir las cosas y al hombre ${ }^{18}$ y en ello el hombre mismo quedaba medido; esto es, para medir, utilizando una regla, siempre se necesitan dos momentos o partes. Sloterdijk es muy claro en este punto: "Lo apolíneo... no mienta otra cosa que la necesidad de dotar, a la amorfa compulsión de las fuerzas dionisíacas y de la diversidad caótica de lo individual, de una forma reguladora sometida a la ley de la 'mesura”" (Sloterdijk 163). Nietzsche es bastante brillante al darse cuenta del porqué del desarrollo matemático de las ciencias en la Modernidad

Matemática. Queremos introducir en la medida de lo posible el rigor y sutileza de la matemática en todas las ciencias, aunque no abrigando la creencia de que nos pueda conducir al conocimiento de las cosas, sino a fin de averiguar nuestra relación humana con las cosas. La matemática sólo es el medio del conocimiento humano general y último (La ciencia jovial 259).

Por tanto, el hombre se volvía en sí mismo en el duplo "sujeto-objeto"; y nacía de este modo la "realidad”, la naturaleza con minúscula, residual, abstracta, fuente de disposición, laboratorio, materia, ley, como eso que "estáahí-ante” el sujeto fuente de toda medición, de todo conocimiento; la naturaleza, así escindida, se volvía en objeto de cuantificación y, por ende, funcionaba como el horizonte de objetivación en donde el hombre experimenta lo que es: la naturaleza como el gran laboratorio, la gran condición de posibilidad de la medida, donde se constituye el experimento que le da al hombre su lugar propio, a saber, ser sujeto. Todo se había vuelto en platonismo o, si se quiere, platonismo "vulgar", es decir, “cristianismo"; ${ }^{19}$ en el fondo, nihilismo, voluntad de nada, de negación de la vida, de la vida inmanente, en el propio instante, con su "sí" que la afirma incluso en el "no" del dolor: "Quien no sólo comprende la palabra 'dionisíaco', sino que se comprende a sí mismo en ella, no necesita ninguna refutación de Platón... - huele la putrefacción” (Ecce homo, 70). ${ }^{20}$

En Nietzsche, para decirlo muy claramente, no hay positivismo alguno como se ha pensado tantas veces, no hay "relación de medida" de ninguna especie, puesto que no se da formalmente pensamiento "dialéctico”, “antitético”, "negativo” y esto

\footnotetext{
${ }^{18}$ No olvidemos que Nietzsche pensaba que la palabra alemana Mensch se relacionaba con la latina mensuratio. Véase (Así habló Zaratustra 101) “Por ello se llama 'hombre’, es decir: el que realiza valoraciones".

${ }^{19}$ La religión en la época de Nietzsche en Alemania era bastante rígida y paralizante de la vida, como ese "topo medio enano" que llevamos todos al caminar por la vida y que nos pesa, nos paraliza y nos envenena del pasaje "De la visión y enigma” de Así habló Zaratustra. Cfr. (Así habló Zaratustra 242-249). “... aunque sobre mí iba sentado ese espíritu, mitad enano, mitad plomo, paralítico; paralizante; dejando caer plomo en mi oído, pensamientos-gotas de plomo en mi cerebro” (F. Nietzsche, Así habló Zaratustra 243).

20 “Wer das Wort 'dionysisch nicho nur begreft, sondern sich in dem Wort 'dionysisch' begreoft, hat keine Widerlegung Platos oder des Christentums oder Schopenhauer nötig - eriecht die Verwesung...”, Ecce homo (Werke, ZB 1110).
} 
es fundamental para poder más o menos barruntar lo que entiende por Naturaleza. Por eso Nietzsche era tan claro cuando nos indicaba que

Una interpretación "científica” del mundo, tal como vosotros la entendéis, podría ser, por tanto, una de las interpretaciones más estúpidas, es decir, la más pobre en significado de todas las interpretaciones posibles del mundo: dicho sea esto al oído y a la conciencia de los señores mecánicos, que hoy día gustan de pasar como filósofos, y que suponen sin reparo alguno que la mecánica es la doctrina de las primeras y últimas leyes sobre las que se tiene que haber construido, como sobre un gran fundamento, toda la existencia (La ciencia jovial 391-392).

Nietzsche señalaba que solamente creería en un "dios bailarín”; ${ }^{21}$ tras ese tipo de dios tenemos que indagar para poder dar con su concepción de la Naturaleza.

\section{NATURALEZA, CUERPO Y DIONISOS}

Un texto de la misma época que El Anticristo ${ }^{22}$ es el Crepúsculo de los ídolos el cual nos agrega un pequeño matiz en su fórmula de la felicidad: ${ }^{23}$ "Fórmula de mi felicidad: un sí, un no, una línea recta, una meta...” (Crepúsculo de los ídolos 36). ${ }^{24}$

Este matiz nietzscheano en la sentencia es fundamental, pues acontece un cambio: "nuestra" felicidad (El Anticristo) es ahora, en el fondo, "mi” felicidad (Crepúsculo); no es la felicidad en abstracto, unilateral, del hombre en general, del moderno. Y, además, ya sabemos por lo que ha dicho en El Anticristo

\footnotetext{
${ }^{21}$ Véase (Kerényi, 105) “... en todas las interpretaciones modernas siguió dominando un rasgo extravagante y explosivo en la imagen de lo dionisíaco. Esto es, sin duda, mérito de Nietzsche, quien no sólo influyó en Otto, sino también otros investigadores 'más sobrios' que veían en lo orgiástico el núcleo de la religión dionisíaca”.

${ }^{22}$ No dejamos de ver que en el nombre de El Anticristo se esconde, como debe ser, su opuesto y afirmativo Dionisos. El libro se podría haber llamado simplemente Dionisos. Pero Nietzsche quería ser "explícito" en su provocación y quería que se "viera” el elemento a superar, esto es, “Cristo" (Cristianismo). El Anticristo es Dionisos, esto es, la superación del nihilismo, la ascensión del nihilismo, su verdad, o como él mismo dice, su "necesidad lógica".

${ }^{23}$ No olvidemos que el mismo día que concluye El Anticristo, es decir, el 30 de septiembre de 1888 (libro que escribió en un mes y que marca para Nietzsche un antes y un después de la humanidad), es el día que escribe el prólogo del Crepúsculo de los ídolos. En realidad, como sabemos hoy, estos dos textos, como otros, son parte del fracasado proyecto de Der Wille zur Macht de Nietzsche; en realidad El Anticristo sería la primera parte de La voluntad de poder. A veces llamaba tanto a esta obra no escrita la Voluntad de poder como al El Anticristo simplemente Umwertung aller Werte, esto es, Transvaloración de todos los valores y este dato lo retomaremos al final del escrito.

24 “Formel meines Glücks: ein Ja, ein Nein, eine gerade Linie, ein Ziel...”, Götzen-Dämmerung (Werke, ZB 949).
} 
explícitamente y en múltiples textos de Así habló Zaratustra que cuando dice “felicidad” está diciendo "vida” (en tanto cuerpo, Naturaleza).

Nietzsche ha salido del laberinto, cual Teseo, en especial del Laberinto del “Minotauro-Kant”, y ha salido por medio del "Hilo de Ariadna”. ${ }^{25}$ ¿Cuál es ese hilo que nos permite dar con la salida del laberinto y así dejar de caminar en la oscuridad, la incertidumbre y el temor? ¿Cómo es posible una "transvaloración de todos los valores” real y efectiva? Más allá del nihilismo, en sentido amplio, ha dado Nietzsche con el camino, pero no cualquier camino (no un camino, como se ha dicho, que aspira a una "meta" a dónde se debe llegar), sino un camino que se hace al andar, en la propia vida, en la propia Naturaleza; solamente allí se da, se cumple la fórmula: jésa es su verdad! Esto es, la fórmula de "nuestra" felicidad, de "nuestra” vida, de "nuestra” Naturaleza es "mi” felicidad, "mi” vida, "mi” Naturaleza; pero en la vida de cada uno en lo más propio de "sí-mismo" (Selbst), con toda su diferencia absolutamente singular y afirmativa; a saber, en lo más propio de su cuerpo. Como brillantemente ve Klossowski

"El cuerpo es el resultado de lo fortuito: no es nada más que el lugar de encuentro de un conjunto de impulsos individuales relativos a ese intervalo que constituye una vida humana, los cuales sólo aspiran a desindividuarse" (Nietzsche y el círculo vicioso 50).

¡He aquí: la Naturaleza! El Hilo de Ariadna es la Naturaleza como cuerpo, pero no un cuerpo unilateral, conceptual, "material”, mecánico, mera negatividad residual del espíritu. ¡No!, sino todo lo contrario. El "sí-mismo” es el cuerpo que emerge, surge, se levanta desde las múltiples fuerzas que se aglutinan caóticamente, en los "pies del danzar de Dionisos"; la mismidad es una mismidad física del cuerpo que somos en esas intensidades; el cuerpo es anterior incluso a nuestro yo, nuestros pensamientos

"El sí-mismo escucha siempre y busca siempre: compara, subyuga, conquista, destruye. El sí-mismo domina y es el dominador también del yo...Detrás de tus pensamientos y sentimientos, hermano mío, se encuentra un soberano poderoso, un sabio desconocido - llámase símismo. En tu cuerpo habita, es tu cuerpo" (Así habló Zaratustra 63). ${ }^{26}$

La Naturaleza como cuerpo como el "verdadero" fundamento, el abismo (Abgrund) como prius ${ }^{27}$ de todo fundamento (Grund), el fondo insondable desde

\footnotetext{
${ }^{25}$ Son muchos los fragmentos y textos de la obra nietzscheana donde se habla de esta idea del Hilo de Ariadna en este sentido; y en especial, como ya hemos dicho, de ver cómo Ariadna es la clave para entender lo dionisíaco.

26 "In deinem Leibe wohnt er, dein Leib ist er" (Werke, ZB 300).

${ }^{27}$ Véase para entender este prius tan caro a ciertas filosofías: "Este carácter de anterioridad podría ser entendido desde la Verhaltenheit de los Beiträge, la cual menciona eso absolutamente separado como renuncia, Verzicht que está en la Anwesenheit y en el Gegenvart, eso que los
} 
donde surge y deja de ser el hombre, el hombre que somos cada uno de nosotros en nuestra felicidad, nuestra vida; en nuestra más propia tierra, nuestra Naturaleza. Cuerpo como el "único" sentido, la "única” meta posible desde donde se da el "sí” y "no", la paz y la guerra, el pastor y el rebaño. Una "meta”, esto es, una "única meta", "único sentido" como dice constantemente Nietzsche en Así habló Zaratustra: "isea el superhombre el sentido de la tierra!...permaneced fieles a la tierra” (39). ${ }^{28}$ De allí que Heidegger tenga razón en 1936 y barruntó lo pensado por Nietzsche respecto del cuerpo y los temples de ánimo

En todo ello vibra el estado corporal, nos eleva y lleva más allá de nosotros mismos, o bien deja al hombre apático y prisionero de sí mismo. No estamos en primer lugar "vivos" y después tenemos un aparato llamado cuerpo, sino que vivimos [leben] en la medida en que vivimos corporalmente [leiben]. Este vivir corporalmente es algo esencialmente diferente del mero estar sujeto a un organismo (Nietzsche, 101).

Estamos en los dominios de lo que Nietzsche llama a veces al final de su obra simplemente con el nombre de un dios griego: "Dionisos”. ¿Por qué llamar a "eso" Dionisos? ¿Por qué llamarlo así cuando el nombre del dios griego estaba asociado dialécticamente, por el propio Nietzsche en su juventud, al otro dios griego llamado Apolo? ¿Es el mismo Dionisos de 1888 de El Anticristo y el Dionisos de El nacimiento de la tragedia de 1872? ¡No es del todo el mismo! $\mathrm{Y}$ tengamos esto siempre presente. Nietzsche en la primavera de 1888 escribe en uno de sus cuadernos de apuntes sobre Dionisos lo siguiente: "En este preciso lugar pongo yo al Dioniso de los griegos: la afirmación religiosa de la vida, de la vida entera...” (Fragmentos póstumos (1885-1889) Vol. IV 538).

Así es como Nietzsche nos dice del dios griego: Dionisos como la “afirmación religiosa de la vida”, de la Naturaleza; el "Sí” por excelencia, que da, que permite la articulación "naturaleza y espíritu”; es este dios el que está mentando el eterno retorno. Es como si este Dionisos final de Nietzsche llevara dentro de sí al Dionisos y Apolo de la juvenil obra El nacimiento de la tragedia. El dios como la "tierra matriz" donde se asienta tanto el sentimiento (la intuición y la oscuridad) como el pensamiento (el concepto y la figuración resplandeciente). El dios mienta ese "permaneced fieles a la tierra" del hombre en "trans”; en tránsito (Übermensch); ese hombre que sale de sí por el carácter abismal de su cuerpo, que es mero desborde dionisíaco. ${ }^{29}$ No solamente venimos de la tierra, sino que vamos hacia ella y lo hacemos por medio de la

constituye, eso que el Maestro Eckhart llamaba 'abegescheidenheit', el ocultamiento del abandono del ser en su propio olvido para dar paso a la presencia del ser, esto es, su retirada, Entzug” (Espinoza, Heidegger y Zubiri. Después del ser y la realidad: el problema del Ereignis).

28 “... Der Übermensch sei der Sinn der Erde...bleibt der Erde treu” (Werke, ZB 280).

${ }^{29}$ De allí la idea del hombre y ese deinón de Antígona. 
tierra misma; el hombre es el permanente caminante de la tierra a la tierra a través de la tierra (estamos en las antípodas de Hegel y su definición de movimiento en la Lógica de la esencia de la Wissenschaft). ${ }^{30}$ ¡Ésa es su definición dinámica! De allí que el hombre dicho de modo radical y propiamente sea "el sentido de la tierra" y no de a prioris, ideas o conceptos. ¿Cuál es esa única meta, esa línea recta, ese no, ese sí, esa vida, esa felicidad, nuestra felicidad, mi felicidad? En cierta forma, ya lo hemos dicho y claramente en este texto: simplemente ¡Dionisos! En el Ecce homo, cuyo comienzo se data explícitamente el 15 de octubre de 1888 (a quince días del prólogo del Crepúsculo y del surgimiento de El Anticristo; y el día que Nietzsche cumplía 44 años), podemos dar con unas huellas aclaratorias a esta "fórmula dionisiaca de mi vida”, de la Naturaleza, para esto citaremos in extenso el texto

\begin{abstract}
-¿Tiene alguien... un concepto claro de lo que los poetas de épocas poderosas denominaron inspiración?... Se oye, no se busca; se toma, no se pregunta quién es el que da... Un éxtasis cuya enorme tensión se desata a veces en un torrente de lágrimas, un éxtasis en el cual unas veces el paso se precipita involuntariamente y otras se torna lento; un completo estar-fuera-de-sí... un abismo de felicidad, en que lo más doloroso y sombrío no actúa como antítesis, sino como algo condicionado, exigido, como un color necesario en medio de tal sobreabundancia de luz; un instinto de relaciones rítmicas, que abarca amplios espacios de formas... Todo acontece de manera sumamente involuntaria, pero como en una tormenta de sentimiento de libertad, de incondicionalidad, de poder, de divinidad [las cursivas son nuestras] (Ecce homo, 97-98).
\end{abstract}

La felicidad, la vida, la Naturaleza sentida en la más "propia tierra" de cada uno, con toda su intensidad, diferencia y singularidad se da en la inspiración. Pero no de cualquier inspiración, por eso el filósofo la describe con tanto detalle; la describe, por así decir, desde dentro de ella misma, pues la analiza desde su propia experiencia en inspiración; inspiración en afirmación (en eterno retorno). La inspiración es una experiencia que Nietzsche nos muestra de manera única; si queremos lo podríamos entender como el temple "originario" nietzscheano por excelencia, pero ese temple originario se da en la actividad originaria del caminar, del vivir; actividad originaria que no tiene que ser entendida como una vuelta al origen. La inspiración no comparece desde una posición teórica en la que debo colocarme para que la pueda describir como acto originario; o sea, no estamos en aguas ni de Fenomenología, ni de reducción eidética, ni tampoco de Hermenéutica, ni de contexto interpretativo, pues no hay sentido que develar ni contexto para analizar. El caminar originario

${ }^{30}$ Véase (Hegel, Ciencia de la lógica 447). "El devenir dentro de la esencia, su movimiento reflexionante, es por tanto el movimiento de nada a nada y, por este medio, de vuelta a sí mismo”. 
de Nietzsche es un caminar existencial de profundas sutilezas y detalles. Como dice el filósofo español Félix Duque muy claramente: “... él es un maestro del matiz, y más: quiere ser él mismo un matiz” (Los buenos europeos. Hacia una filosofía de la Europa contemporánea 80). Y Nietzsche es así de claro al final de sus días lúcidos en su Ecce homo

No soporto a esta raza, con quien siempre se está en mala compañía, que no tiene mano para las nuances [matices] — iay de mí!, yo soy una nuance [matiz] - , que no tiene esprit [ligereza] en los pies y ni siquiera sabe caminar... A fin de cuentas, los alemanes carecen en absoluto de pies, sólo tienen piernas (133).

Esto es, camina realmente, por ejemplo, junto a su madre y hermana en Naumburg en 1850 cuando tiene 6 años y bajo una torrencial lluvia; junto a los Wagner en la bella y apacible finca de Triebschen, al lado de Lucerna, en mayo de 1869 con 25 años; junto al Lago Silvaplana a 6000 pies de altura en el verano de agosto de 1881 con 37 años; junto a Lou Salomé en Italia, en el Lago de Orta en mayo de 1882 con 42 años; en Turín a fines de 1888 con 44 años bajo una tremenda crisis médica y existencial, etc.; así de preciso es el caminar de Nietzsche; solamente allí se da la inspiración como lo originario mismo de la vida: mi vida, nuestra vida, mi Naturaleza, nuestra Naturaleza. Se camina desde instantes, desde ciertas rutas, desde ciertas perspectivas. Son ellas, las múltiples vías, las que constituyen lo originario, lo especifican en cierto modo; le dan una especie de estabilización y homogeneidad ulterior: "El perspectivismo es solamente una forma compleja de la especificidad” (Fragmentos póstumos (1885-1889) Vol. IV 603).

En esto radica la Naturaleza, a saber, en perspectivas, fuerzas, instantes que se entrecruzan. Estamos ante la única felicidad que no espera ni aspira a nada más allá de sí, la felicidad que no es trasmundana, de otro mundo, que ya no tiene nada del "sí" y "no" de los modernos, sino del "sí” y "no" en la vida dionisiaca y abismal del instante; dicho de un modo más bello en el Ecce homo cuando nos hablaba de "su" inspiración.

Un abismo de natural felicidad, una felicidad desfondada que no anhela nada, porque no hay meta que se anhele, una felicidad en éxtasis, en un estar-fuera-de-sí (Aussersichsein); una felicidad espaciosamente corporal, que se sale en tensiones y fuerzas; y en ella el "no" del dolor no se siente como negativo, como sombra que nos pesa, que nos hunde, que nos atemoriza, sino con la necesidad de ser parte de la sobreabundancia de la luz de la Naturaleza. Ella no es solamente un fondo oscuro romántico de tinte postkantiano, sino que es afirmación luminosa de las trazas de las fuerzas mismas. Estamos en la Naturaleza como instinto (Trieb) de relaciones rítmicas que fluyen incondicionalmente y constituyen las cosas en sus "bailes” y al hombre en su "caminar muscular"; si se quiere con la Naturaleza estamos ante fuerzas y nada más que fuerzas. Nietzsche lo dice así en uno de sus últimos fragmentos de finales de 1888 
... la fuerza como sentimiento de dominio en los músculos, como elasticidad y placer en los movimientos, como danza, ligereza y presto [...] la fuerza como placer al demostrar la fuerza, como pieza de maestría, aventura, intrepidez, indiferencia (556).

La Naturaleza es entendida como una danza ligera de fuerzas intrépidas, de sentimientos corporales, indiferentes. La Naturaleza está constituida por sistemas de relaciones, en inespecificidad, libres y creativas. No hay cosas esenciales como ensimismadas (vueltas sobre sí, reflexionadas). Las cosas son ritmos que fluyen y se entrecruzan (por eso las llama "enamoradas"); las cosas son laberínticas, en múltiples rutas, que incluso a veces no conducen a ningún lugar; se hace camino en cada perspectiva, en cada traza, en cada línea recta, en cada meta. La Naturaleza es ese plural constitutivo de fuerzas que se llama "sí-mismo", cuerpo, pero en sentido fuerte, impresivo, abierto y nunca de suyo ya organizado, sino siempre por hacer. ${ }^{31}$ La Naturaleza entendida sin ningún carácter positivista, ni materialista, ni idealista, ni realista, ni romántico, ni dogmático, ni teológico, ni burgués, a saber, sin ningún carácter nihilista. La Naturaleza como un abismo de fuerzas que fluyen, como el fundamento de todos los fundamentos, a saber, lo desfundamentado, lo desfondado. "La naturaleza y el espíritu" se fundan en el abismo "profundo”, por ser superficial, de la Naturaleza dinámica.

Sin embargo, ese rasgo profundo no es kantiano-romántico, de aquí la diferencia con Schelling, Schlegel, Schopenhauer, Wagner y tantos otros. Como Nietzsche dice en El caso Wagner de 1888: “¡Para eso hace falta quedarse plantado con gallardía en la superficie, en los pliegues, en la piel, en el Olimpo entero de la apariencia! Esos griegos eran superficiales... por profundos" (Nietzsche contra Wagner 97). El rasgo profundo es la jovialidad (Heiterkeit) misma de la Naturaleza en esa trama de "dioses bailarines", de fuerzas dinámicas que avanzan y retroceden, que se mueven no con rapidez constante y uniforme, sino siempre acelerada, siempre venciendo la inercia homogénea de la mismidad simétrica de la Naturaleza que no busca reposo alguno. El paso a veces rápido y a veces lento es el modo del ritmo y tensiones de las fuerzas nietzscheanas de la Naturaleza. ¡Esto es lo profundo de la Naturaleza! Esto es, no tiene la Naturaleza nada "en sí", sino todo lo contrario; es estar-fuera-de-sí, éxtasis (Ausser-sich-sein) tal como el dios Dionisos que se sentía en Grecia, como señala Walter Otto, ${ }^{32}$ como una máscara que mentaba toda su ser como mera apariencia (Erscheinung).

${ }^{31}$ Como diría Deleuze en El Anti-edipo: un “Cuerpo sin órganos”. Véase (Deleuze y Guattari, El Anti-Edipo. Capitalismo y esquizofrenia 17) "El cuerpo lleno sin órganos es lo improductivo, lo estéril, lo engendrado, lo incosumible".

${ }^{32}$ Véase (Otto 67). "La sobrecogedora irrupción del dios y su inevitable presencia han encontrado un símbolo aún más expresivo que los ritos que se han comentado hasta ahora, una imagen que entraña el complejo enigma de su ambigüedad y, con él, la locura. Se trata de la máscara”. 
El "verdadero" fundamento, a saber, el cuerpo, es siempre lo abismal que aparece en fuerzas rítmicas; el cuerpo es en sí-mismo inespecífico, desfondado, pues no podemos cerrarlo, acabarlo, definirlo, acotarlo; se resiste a cualquier tipo de clausura; es la inespecificidad misma que trasciende las cosas, es su apertura. El cuerpo está de suyo abierto formalmente. En ese abismo de mi cuerpo, de mi vida, nuestra vida: ¡la felicidad!, ¡la Naturaleza!, puesto que allí mismo el "no”, el dolor más sombrío no actúa como antítesis. Y esto no lo olvidemos. El "no" en este abismo no tiene carácter antitético, no es dialéctico, negativo, lógico; no hay posibilidad alguna que sea sintetizado dialécticamente por la razón, pues ella misma está ya fundada por el abismo, el cuerpo, Dionisos. Este "no" es necesario, pero tiene la necesidad del color en la luz, en la gran luz, en el gran "Sí" de la luminosidad. Con esto Nietzsche ya no mantiene esa "ingenua" antítesis de juventud entre Dionisos y Apolo; pero era una antítesis que operaba con cierta finalidad, diríamos, pedagógica para los jóvenes filólogos alemanes. ${ }^{33}$ Esa “contraposición desorientadora” (Colli 27), como la llama Giorgio Colli; de un joven filólogo y académico de la Universidad de Basilea bajo el influjo del romanticismo de Wagner y del pesimismo de Schopenhauer; Nietzsche mismo estaba tocado en este momento por el "espíritu alemán”; el antitético, el dialéctico. Ahora, al final de su lúcida vida, estamos ante un radical Dionisos-Apolo que no lleva negatividad, ni dialéctica alguna. Es un Dionisos que es en sí mismo la sobreabundancia de luz; un Dionisos que resplandece. Es un Dionisos mucho más cercano a Grecia que el Dionisos “alemán” (con tintes de Wotan y Thor de la mitología escandinava alemana) que Nietzsche enseñaba en su juventud en Basilea.

El caminante camina en Dionisos, en la Naturaleza. Se camina en un DionisosApolo, esto es, en un completo éxtasis de la exterioridad, de la jovialidad más profundo del juego del baile de fuerzas terrestres que se entrecruzan y ligan entre sí. Se está en un Dionisos-Apolo con clarísima conciencia, una conciencia sentiente de todo mi cuerpo, hasta los “dedos de los pies”, como diría Nietzsche. Se está en la luz de mi propio cuerpo atravesado por estremecimientos resplandecientes. Se está en la Naturaleza danzando en ella sobre los pies del azar. Y se danza dando saltos, a un paso distinto; el paso del caminante en inspiración es un paso al ritmo, al flujo acelerado; cambiando de velocidad; no hay tiempo para el caminar pausado, constante y homogéneo. El paso es avanzando ya lento, ya rápido; es un paso como el caminar del Sileno o del Dionisos embriagado; es un paso cojeando (en el ritmo del yambo). Los pies del azar, esto es, la métrica más propia de Dionisos. El caminante hace camino al andar, pues el camino en y por sí mismo no existe; pues sería una vez

\footnotetext{
${ }^{33}$ Véase (Vega 44-45) Aquí Vega lo explica muy bien: "En El nacimiento de la tragedia, se asocia la necesaria destrucción del principium individuatonis, es decir, el instinto de lo apolíneo, a la fragmentación del cuerpo de Dionisos a manos de los Titanes”.
} 
más caer en simple nihilismo: "Un ensayar y un preguntar fue todo mi caminar... ¡ $E l$ camino, en efecto, - no existe!” (Colli, 303).

El caminar del bailarín es caminar en la experiencia de Dionisos; es un caminar como de un inocente niño; un niño que en su preguntar, remueve y cambia lo establecido como lo valórico y correcto; y así transvalora, el hombre, asumiendo la realidad en la liviandad del instante. El camino solamente es en el caminar de ese ensayar de la existencia humana. Y de allí ese sentimiento de la inspiración que nos arrebata, nos embarga, nos arrastra, nos conmueve.

Ese sentimiento de libertad, de incondicionalidad, de poder, esto es, de divinidad, es el "Blasón de necesidad del eterno Sí del ser", del eterno "sí" retornante de la Naturaleza; de Dionisos. Es muy interesante analizar someramente lo que da de sí ese sentimiento de libertad, sentimiento incondicional; da la divinidad, a saber, Dionisos. La Naturaleza se reconcilia con la Divinidad sin la necesidad aniquilante de Schopenhauer, ni la fuerza oscura negativa de Wagner, es decir, es una reconciliación sin nihilidad paralizante; y se reconcilia sin la necesidad del cristianismo absolutista de Schelling y de Hegel, es decir, sin dialéctica negativa. Lo involuntario al nivel de lo más propio de la voluntad de cada uno; una necesidad que perfora todo acto volitivo.

\section{CONCLUSIÓN}

Nietzsche en plena desazón existencial (desazón de toda una época) sigue pensando en el "sí” y "no" moderno y cómo deben ser superados

Los alemanes se hallan inscritos en la historia del conocimiento sólo con nombres ambiguos, no han producido nunca más que falsarios “inconscientes" (-Fichte, Schelling, Schopenhauer, Hegel, Schleiermacher merecen esa palabra, lo mismo que Kant y Leibniz, todos son meros fabricantes de velos [Schleiermacher] (Ecce homo, 131).

Y aquí vemos lo que siempre repite el filósofo en Zaratustra, a saber, que el carácter divino siempre es múltiple, bailarín ligero, sonriente; es un carácter "más allá de lo bueno y lo malo"; "más allá del hombre y del tiempo”, pero el ser más allá de lo moderno implica que es totalmente acá; en el aquí mismo de hombre y Naturaleza. Es un carácter abismalmente afirmativo que toma lo fatal, necesario, determinado, destinado y lo libre, ligero, bailarín como lo más propio de cada uno. Y solamente desde allí es posible el "mediodía”, donde la sombra es más corta y el hombre se siente caminante en la naturaleza del dios borracho.

$\mathrm{Si}$ se ha entendido, la fórmula nietzscheana de la felicidad mienta la afirmación de la vida, a saber, la Naturaleza en su carácter físico de ser en el dinámico fluir de fuerzas que acontecen en el instante y en esto son fuerzas propiamente afirmativas. Ante esto ya no es posible entender la Naturaleza como el lugar de las leyes. La categoría de ley se queda estrecha para mentar “esencialmente” lo que sea la Naturaleza. Nietzsche era así de tajante: 
"Guardémonos de decir que hay leyes en la naturaleza. Sólo hay necesidades: jaquí no hay nadie que mande, nadie que obedezca, nadie que infrinja las leyes" (La ciencia jovial 202).

Es en el instante de afirmación de las fuerzas de la Naturaleza que se asume el duplo "naturaleza y espíritu". Y ese instante es nuestra vida, mi vida, nuestra felicidad, mi felicidad, nuestra Naturaleza, mi cuerpo; a saber, "un sí, un no, una línea recta, una meta". La fórmula de nuestra felicidad es la fórmula del pensamiento abismal, la suprema afirmación de la Naturaleza. Con esto, en definitiva, Nietzsche ha asumido a Lutero, a Kant, a Wagner; ha asumido, con su actitud, la modernidad, a Europa, a la historia de un error. Y así queda echada la suerte para el siglo XX. En Nietzsche se abre un nuevo horizonte que atraviesa taladrando los últimos muros de la modernidad. Y es entre esos escombros de lo moderno en donde pensadores como Bergson, Ortega, Foucault, Deleuze, y tantos otros se hacen cuestión. Desde Nietzsche surge el horizonte problemático de la existencia; surge formalmente una nueva Europa. La Europa cansada de cierto todo que se vuelve homogéneo es cosa del pasado; solamente ahora estamos viviendo en la Naturaleza; entendida ésta como relaciones, redes.

Para finalizar este escrito, hay que señalar que estamos de acuerdo con el pensamiento de Nietzsche, pues nos señala rotundamente que nadie puede ir contra la Naturaleza, sería anti-natural ya pensarlo, pero no olvidemos que de esa anti-naturalidad la humanidad ha bebido por siglos

$$
\begin{aligned}
& \text {...no es posible “denaturer la nature" } \\
& \text { [desnaturalizar la naturaleza] (La ciencia } \\
& \text { jovial, 568). }
\end{aligned}
$$

Pontificia Universidad Católica de Valparaíso* Instituto de Filosofía

Avda. El Bosque 1290, Sausalito, Viña del Mar (Chile) respinoz@ucv.cl

Pontificia Universidad Católica de Valparaíso** Instituto de Cs., Religiosas

Avda. El Bosque 1290, Sausalito, Viña del Mar (Chile) esteban.vargas@ucv.cl

Pontificia Universidad Católica de Valparaíso*** Escuela de Psicología Avda. El Bosque 1290, Sausalito, Viña del Mar (Chile) pascorra@ucv.cl 
Nietzsche y la concepción de la naturaleza como cuerpo

\section{BIBLIOGRAFÍA}

Aristóteles. Física Libros I-II. Buenos Aires: Biblos, 1993.

Cano, G. "Estudio introductorio". Nietzsche, F. Nietzsche I. Madrid: Gredos, 2009:XLI.

Colli, G. Después de Nietzsche. Barcelona: Anagrama, 1978.

Daraki, M. Dioniso y la diosa Tierra. Madrid: Abada, 2005.

Deleuze, G. Nietzsche y la filosofía. Barcelona: Anagrama, 2002.

Deleuze, G.; F. Guattari. El Anti-Edipo. Capitalismo y esquizofrenia. Barcelona: Paidós, 1985.

Duque, F. Los buenos europeos. Hacia una filosofía de la Europa contemporánea. Oviedo: Nobel, 2003.

Espinoza, R. “'En torno al problema de Dios'... desde la Biografía del joven Zubiri”. The Xavier Zubiri Review 8 (2006), pp. 147-159.

Espinoza, R. "Estructura” AA., VV. Claude Lévi-Strauss en el pensamiento contemporáneo. Buenos Aires: Colihue, 2009.

Espinoza, R. "Heidegger y Zubiri. Después del ser y la realidad: el problema del Ereignis”. Espinoza , R. y J. Nicolás. Zubiri ante Heidegger. Barcelona: Herder, 2008:215.

Foucault, M.; G. Deleuze. Theatrum Philosophicum seguido de repetición y diferencia. Barcelona: Anagrama, 1995.

Hegel, G. W. F. Ciencia de la lógica. Madrid: Abada, 2011.

Hegel, G. W. F. Fenomenología del espíritu. Madrid: Abada, 2010.

------- Lecciones sobre la filosofía de la historia natural. Barcelona: Altaya, 1997.

Heidegger, M. Nietzsche. Madrid: Destino, 2005.

Husserl, E. Ideas relativas a una fenomenología pura y una filosofía fenomenológica I. México: F. C. E., 1949.

Kant, I. Principios metafísicos de la ciencia de la naturaleza. Madrid: Alianza, 1989.

Kerényi, K. Dionisio. Raíz de la vida indestructible. Barcelona: Herder, 1998.

Klossowski, P. Nietzsche y el círculo vicioso. Madrid: Arena Libros, 2004.

Lenin, V. Materialismo y empiriocriticismo. Moscú: Progreso, 1979.

Nietzsche, F. Más allá del bien y del mal. Madrid: Alianza, 2011.

Fragmentos póstumos (1885-1889) Vol. IV. Madrid: Tecnos, 2006.

------- Ecce homo. Madrid: Alianza, 2006.

Nietzsche contra Wagner. Madrid: Siruela, 2002.

------ Nietzsche contra Wagner. Madrid: Siruela, 2002.

------- La ciencia jovial. Madrid: Biblioteca Nueva, 2001.

------ Poesía Completa (1869-1888). Madrid: Trotta, 2000.

------- La filosofía en la época trágica de los griegos. Madrid: Valdemar, 1999.

------- Así habló Zaratustra. Madrid: Alianza, 1998. 
Ricardo Espinoza, Esteban Vargas, Paula Ascorra

------- Crepúsculo de los ídolos. Madrid: Alianza, 1991.

------- El Anticristo. Madrid: Alianza, 1990.

------- Werke in drei Bänden, Zweiter Band. München: Verlag Carl Hansen, 1966.

Nietzsche, Friedrich. Así hablo Zaratustra. Madrid: Alianza, 1998.

Otto, W. Dionisio. Madrid: Siruela, 1997.

Sloterdijk, P. El pensador en escena. El materialismo de Nietzsche. Valencia:

Pre-Textos, 2000.

Vega, A. Sacrificio y creación en la pintura de Rothko. Madrid: Siruela, 2010.

Zubiri, X. Espacio. Tiempo. Materia. Madrid: Alianza, 2008.

------ Naturaleza, Historia, Dios. Madrid: Alianza, 2004. 